\title{
Spectral and Thermal Properties of Biofield Energy Treated Cotton
}

\author{
Mahendra Kumar Trivedi ${ }^{1}$, Rama Mohan Tallapragada ${ }^{1}$, Alice Branton ${ }^{1}$, Dahryn Trivedi ${ }^{1}$, \\ Gopal Nayak ${ }^{1}$, Rakesh Kumar Mishra ${ }^{2}$, Snehasis Jana ${ }^{2, *}$ \\ ${ }^{1}$ Trivedi Global Inc., Henderson, USA \\ ${ }^{2}$ Trivedi Science Research Laboratory Pvt. Ltd., Bhopal, Madhya Pradesh, India
}

\section{Email address:}

publication@trivedisrl.com (S. Jana)

\section{To cite this article:}

Mahendra Kumar Trivedi, Rama Mohan Tallapragada, Alice Branton, Dahryn Trivedi, Gopal Nayak, Rakesh Kumar Mishra, Snehasis Jana. Spectral and Thermal Properties of Biofield Energy Treated Cotton. American Journal of Energy Engineering. Vol. 3, No. 6, 2015 , pp. 86-92. doi: 10.11648/j.ajee.20150306.12

\begin{abstract}
Cotton has widespread applications in textile industries due its interesting physicochemical properties. The objective of this study was to investigate the influence of biofield energy treatment on the spectral, and thermal properties of the cotton. The study was executed in two groups namely control and treated. The control group persisted as untreated, and the treated group received Mr. Trivedi's biofield energy treatment. The control and treated cotton were characterized by different analytical techniques such as differential scanning calorimetry (DSC), thermogravimetric analysis (TGA), fourier transform infrared (FT-IR) spectroscopy, and CHNSO analysis. DSC analysis showed a substantial increase in exothermic temperature peak of the treated cotton $\left(450^{\circ} \mathrm{C}\right)$ as compared to the control sample $\left(382^{\circ} \mathrm{C}\right)$. Additionally, the enthalpy of fusion $(\Delta \mathrm{H})$ was significantly increased by $86.47 \%$ in treated cotton. The differential thermal analysis (DTA) analysis showed an increase in thermal decomposition temperature of treated cotton $\left(361^{\circ} \mathrm{C}\right)$ as compared to the control sample $\left(358^{\circ} \mathrm{C}\right)$. The result indicated the increase in thermal stability of the treated cotton in comparison with the control. FT-IR analysis showed an alterations in $-\mathrm{OH}$ stretching $\left(3408 \rightarrow 3430 \mathrm{~cm}^{-1}\right)$, carbonyl stretching peak $\left(1713-1662 \mathrm{~cm}^{-1}\right), \mathrm{C}-\mathrm{H}$ bending (1460-1431 $\left.\mathrm{cm}^{-1}\right)$, - $\mathrm{OH}$ bending $\left(580-529 \mathrm{~cm}^{-1}\right)$ and $-\mathrm{OH}$ out of plane bending $\left(580-529 \mathrm{~cm}^{-1}\right)$ of treated cotton with respect to the control sample. CHNSO elemental analysis showed a substantial increase in the nitrogen percentage by $19.16 \%$ and $2.27 \%$ increase in oxygen in treated cotton as compared to the control. Overall, the result showed significant changes in spectral and thermal properties of biofield energy treated cotton. It is assumed that biofield energy treated cotton might be interesting for textile applications.
\end{abstract}

Keywords: Cotton, Biofield Energy Treatment, Thermal Analysis, Fourier Transform Infrared Spectroscopy, CHNSO Analysis

\section{Introduction}

Cotton is the most popularly used textile fiber due to its easy availability, low cost as well as good mechanical and physical properties. Cotton is mainly derived from a shrub that is native to tropical and subtropical regions around the word, including Africa, USA, and India [1]. The two main product that are derived from the cotton plant is cotton fiber and cottonseed [2-4]. The main component of cotton is cellulose that is the most abundant natural polymer on Earth [5]. It is the renewable biopolymer of outstanding properties and variety of useful applications [5]. Cotton is mainly used as a material for the manufacture of textile fabrics such as towel, robes, jeans, shirts, etc. Textile industries use the cotton fibers for the production of these materials by weaving and knitting process. Cotton has diverse applications in the medical field ranging from a single-thread suture to the composites for the bone replacement [6]. Cotton-based textiles have been used to prevent the growth of microorganisms [7-8]. Moreover, it was shown that cotton has electric and dielectric behavior. Additionally, cotton based fibers have attracted significant attention as a phase change materials (PCMs) [9]. During early 1980's under the National Aeronautics and Space Administration (NASA) research program PCMs capsules were embedded in textile structure to improve their thermal 
performance [10]. It was used as fabric in the astronaut space suite to provide improved thermal protection against the extreme temperature fluctuations in the outer space [10]. Hence, in order to use cotton-based textile for these applications their thermal and physical stability should be improved. Moreover, the chemical processing of cotton is difficult because this natural polymer is not meltable as well as it is insoluble in most of the available solvents due to strong hydrogen bonds and partially crystalline nature [11]. Many research groups in past few decades have devoted significant attention on modification of cotton for various applications. Yin et al. reported the chemical modification of cellulose carbamate using supercritical carbon dioxide and reported that this method has remarkably increased the nitrogen content in the modified polymer [5]. Recently, cotton fabrics were chemically modified with polyamidoamine dendrimer to yield antimicrobial and efficient polymer materials for ink jet printing [12]. Zhao et al. reported the carboxymethylation of cotton and elaborated that their high water absorbency maintains its fabric structure makes them potential candidates for wound therapy. El-gandy et al. modified the cotton fabrics by grafting with acrylic acid, acrylonitrile under gamma radiation treatment [13]. However, all these methods are not cost effective, hence some alternative strategies should be designed which can modify the physical and thermal properties of cotton. Recently, biofield energy treatment was used as an effective approach for modification of physicochemical properties of metal [14], ceramic [15] and polymers [16]. Hence, authors planned to investigate the impact of biofield treatment on spectral and thermal properties of cotton.

Energy medicine, energy therapy, and energy healing are the divisions of alternative medicine. It is believed that healers can channel the healing into the patients and confer positive results. Moreover, The National Centre for Complementary and Alternative Medicine/National Institute of Health (NCCAM/NIH), has authorized the use of this therapy in health care sector [17]. Biofield energy therapy is known as a treatment method that embraces an improvement in people's health and well-being by effectively interrelating with their biofield [18]. It is believed that good health of a human being entirely depends on the perfect balance of bioenergetic fields [19]. Thus, it is envisaged that human beings have the ability to harness the energy from the surrounding environment/Universe and can transmit into any object (living or non-living) around the Globe. The object(s) always receive the energy and responding in a useful manner that is called biofield energy. Mr. Trivedi is a well-known biofield expert who can transform the characteristics in various research fields such as biotechnology [20] and microbiology [21]. This biofield energy treatment is also known as The Trivedi Effect ${ }^{\mathbb{B}}$.

Hence, by considering the outcomes of unique $\mathrm{Mr}$. Trivedi's biofield energy treatment and excellent properties of cotton, this work was embarked on to investigate the impact of this treatment on spectral and thermal properties of cotton.

\section{Materials and Methods}

Cotton was procured from Sigma Aldrich, USA. The sample was divided into two parts; one was kept as the control sample while the other was subjected to Mr. Trivedi's unique biofield energy treatment and coded as treated sample. The treated sample was in sealed pack and handed over to Mr. Trivedi for biofield energy treatment under laboratory condition. Mr. Trivedi gave the energy treatment through his unique energy transmission process to the treated samples without touching it. The control and treated samples were analyzed using various analytical techniques such as differential scanning calorimetry, thermogravimetric analysis, fourier transform infrared spectroscopy, and CHNSO analysis.

\subsection{Differential Scanning Calorimetry (DSC)}

The control and treated cotton samples were analyzed using Pyris-6 Perkin Elmer DSC at a heating rate of $10^{\circ} \mathrm{C} / \mathrm{min}$ and the air was purged at a flow rate of $5 \mathrm{~mL} / \mathrm{min}$. The predetermined amount of sample was kept in an aluminum pan and closed with a lid. A reference sample was prepared using a blank aluminum pan. The percentage change in latent heat of fusion was calculated using following equations:

$$
\begin{gathered}
\% \text { change in Latent heat of fusion } \\
=\frac{\left[\Delta \mathrm{H}_{\text {Treated }}-\Delta \mathrm{H}_{\text {Control }}\right]}{\Delta \mathrm{H}_{\text {Control }}} \times 100
\end{gathered}
$$

Where, $\Delta \mathrm{H}_{\text {Control }}$ and $\Delta \mathrm{H}_{\text {Treated }}$ are the latent heat of fusion of control and treated samples, respectively.

\subsection{Thermogravimetric Analysis-Differential Thermal Analysis (TGA-DTA)}

A Mettler Toledo simultaneous TGA and differential thermal analyzer (DTA) was used to investigate the thermal stability of control and treated cotton samples. The heating rate was $5^{\circ} \mathrm{C} / \mathrm{min}$, and the samples were heated in the range of room temperature to $400^{\circ} \mathrm{C}$ under air atmosphere.

\subsection{FT-IR Spectroscopy}

The FT-IR spectra were recorded on Shimadzu's Fourier transform infrared spectrometer (Japan) with the frequency range of $4000-500 \mathrm{~cm}^{-1}$. The predetermined amount of sample was mixed with potassium bromide $(\mathrm{KBr})$, and $\mathrm{KBr}$ pellets were prepared by pressing under the hydraulic press.

\subsection{CHNSO Analysis}

The control and treated cotton were analyzed for their elemental composition ( $\mathrm{C}, \mathrm{H}, \mathrm{N}, \mathrm{O}, \mathrm{S}$ etc.). The powdered polymer samples were subjected to CHNSO Analyser using Model Flash EA 1112 Series, Thermo Finnigan Italy. 


\section{Results and Discussion}

\subsection{DSC Characterization}
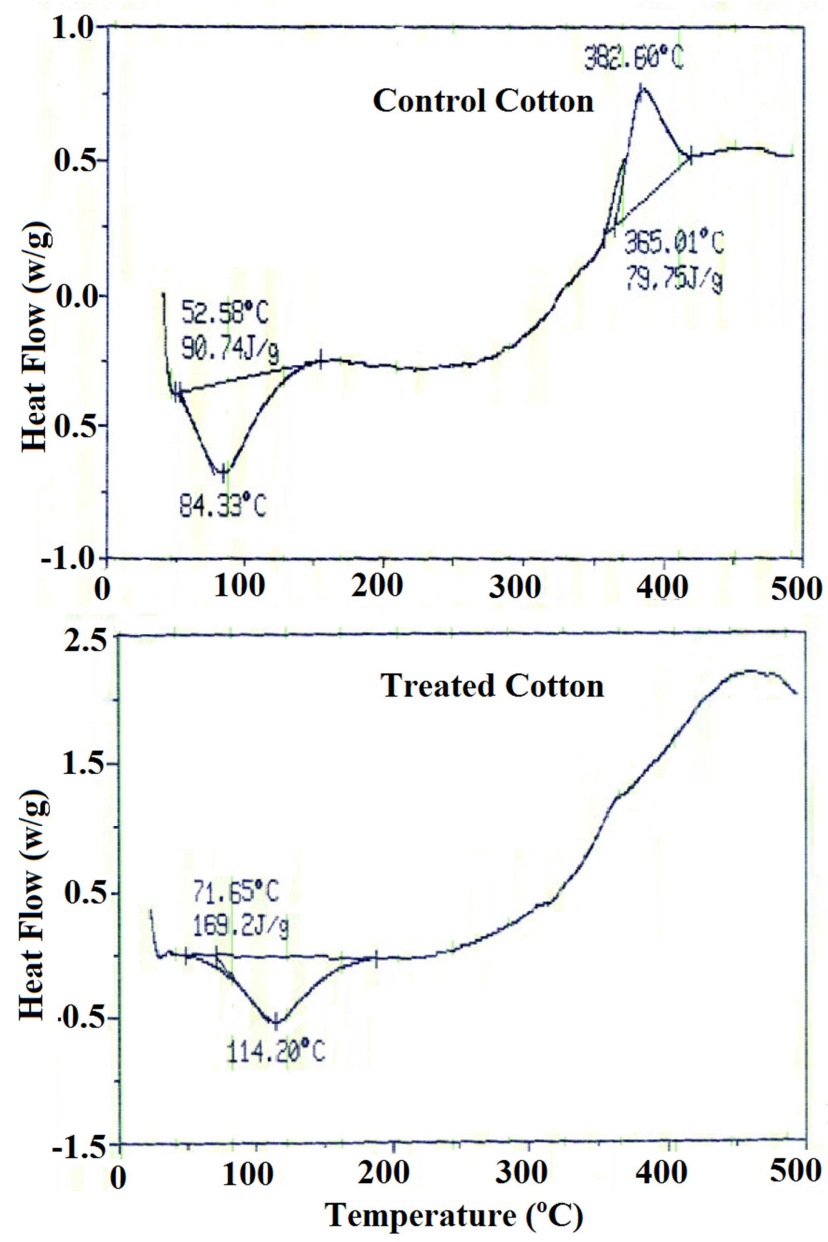

Fig. 1. DSC thermogram of control and treated Cotton.

DSC thermogram of control and treated cotton sample are presented in Figure 1. DSC thermogram of control cotton showed an endothermic peak at $84.33^{\circ} \mathrm{C}$ which was associated with the elimination of bound water. The DSC thermogram of control sample showed an exothermic peak at $382^{\circ} \mathrm{C}$. This exothermic peak was may be due to crystallization or decomposition of cotton leading to the formation of levoglucosan and other volatile products. Potter reported that most of the exothermic events in DSC of textile fibers are due to crystallization and decomposition of the polymer network [22]. Whereas, the biofield treated cotton also exhibited an endothermic peak at $114.20^{\circ} \mathrm{C}$ that was associated with moisture elimination from the sample. The DSC thermogram showed the exothermic peak at around $450^{\circ} \mathrm{C}$. This was again due to decomposition of cotton and volatilization of levoglucosan in the sample [23]. Calamari et al. during their work on the cotton ball and plant trash reported a similar exothermic peak in DSC thermogram. They proposed that this exothermic peak was due to $\beta$ cellulose decomposition in the sample [24]. It is worth noting here that this exothermic peak was significantly increased in the treated sample. This may be inferred as an increase in thermal stability of the treated sample as compared to the control cotton.

The enthalpy of fusion was obtained from the DSC thermogram of control and treated cotton. The enthalpy change of a material is known as energy absorbed during the phase change of a material from solid to liquid phase. The enthalpy of fusion of control cotton was $90.74 \mathrm{~J} / \mathrm{g}$ and it was increased up to $169.2 \mathrm{~J} / \mathrm{g}$ in the treated cotton. The result suggested the $86.47 \%$ increase in enthalpy of fusion of the treated cotton as compared to control sample. Recently, from our group it was reported that biofield energy treatment on monoterpenes (thymol and menthol) altered the latent heat of fusion as compared to the control sample [25]. Hence, it is assumed that biofield energy treatment might alter the internal energy that led to increase in enthalpy of fusion of treated cotton.

\subsection{TGA-DTA}

DTA thermogram of control and treated cotton is presented in Figure 2. DTA thermogram of control sample showed an endothermic transition due to water elimination at around $48^{\circ} \mathrm{C}$. DTA thermogram of control sample showed second endothermic transition at $358^{\circ} \mathrm{C}$. This was due to thermal decomposition of the cellulosic content present in the cotton sample. However, the DTA thermogram of treated cotton also showed two endothermic peaks at $50^{\circ} \mathrm{C}$ and $361^{\circ} \mathrm{C}$. The former endothermic inflexion was due to dehydration of the moisture, and the later peak was due to thermal decomposition of the cellulose in the sample. Joseph et al. reported that in the case of cotton polymer fabric the first step may be attributed to the thermo-oxidative degradation, and this decomposes during the second step thermal degradation process [26]. The results suggested the increase in thermal decomposition temperature of the treated cotton as compared to control. This demonstrated the high thermal stability of treated cotton after the biofield treatment.

TGA of treated sample was carried out to get further insights about the thermal stability of the sample. TGA thermogram of treated cotton is shown in Figure 3, and it showed one-step thermal degradation pattern. The TGA thermogram of treated cotton showed onset temperature at $242.55^{\circ} \mathrm{C}$ and this thermal degradation process was terminated at $391.35^{\circ} \mathrm{C}$. The result showed around $76 \%$ of weight loss during this thermal event. Since, the treated cotton started to degrade thermally only at $242^{\circ} \mathrm{C}$ that may be associated with good thermal stability of the treated sample. Yue suggested that mercerization process substantially increased the thermal stability of the treated cellulose as compared to control sample. They suggested that due to the strong interaction of the $-\mathrm{OH}$ group in cellulose required high energy to start the thermal degradation process [27]. It was reported that thermal properties of textiles are most important and desired features for their applications [28, 29]. For example, thermal insulation determines the elementary function of the garments. Thermal insulation is a key parameter for determining apparel comfort for the user. Hence, it is assumed that biofield energy treated cotton due to good thermal stability could be utilized for fabrication of textile fabrics. 


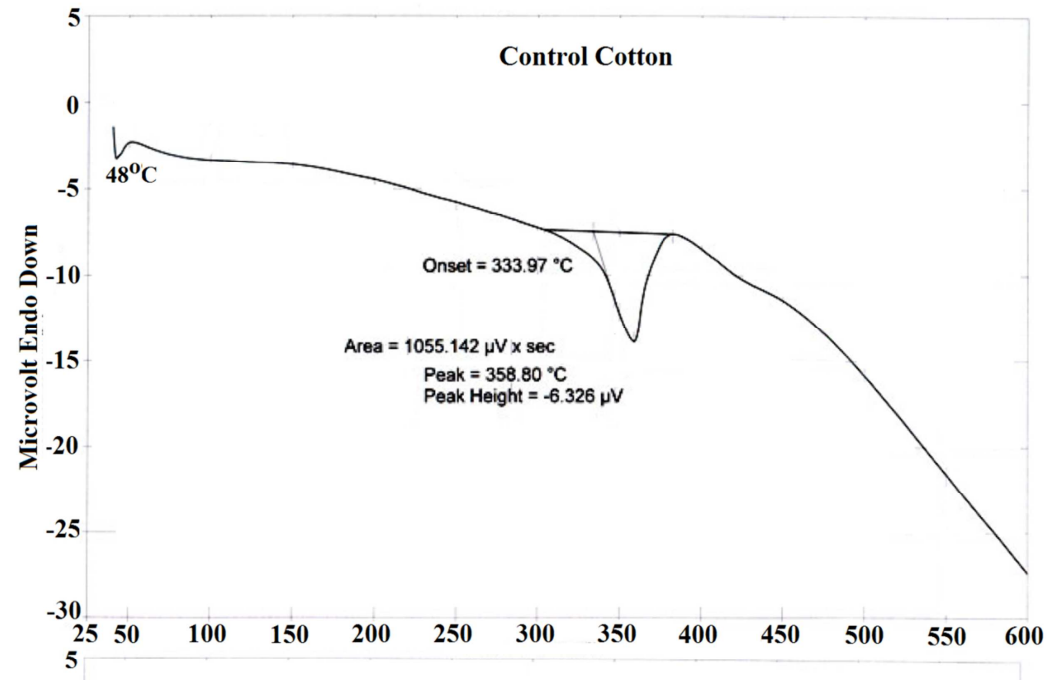

Treated Cotton

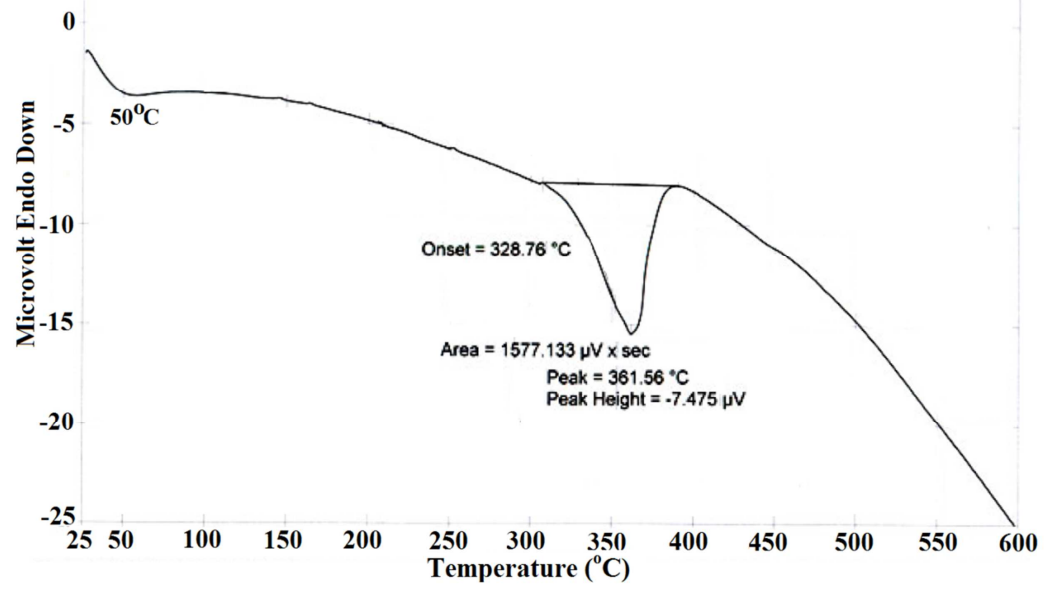

Fig. 2. DTA thermograms of control and treated Cotton.

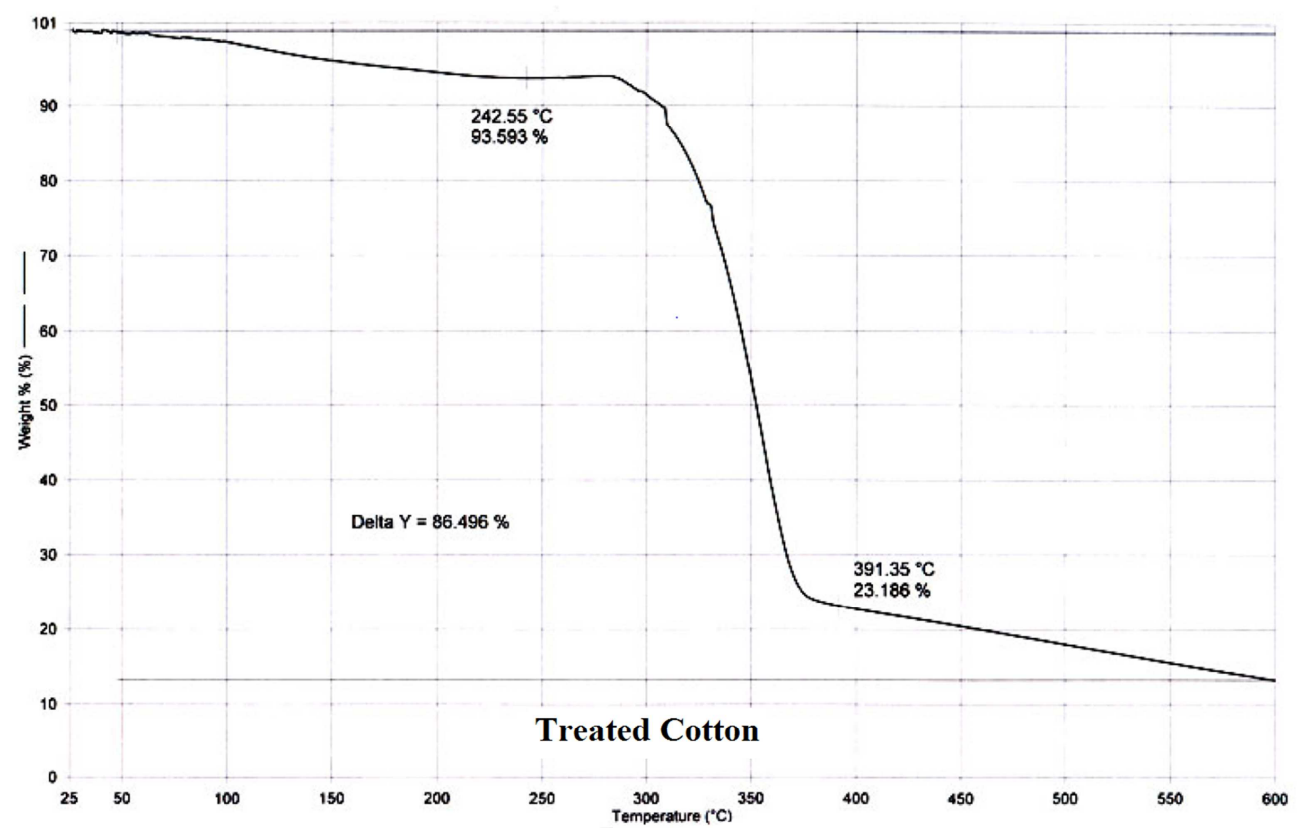

Fig. 3. TGA thermogram of treated Cotton. 


\subsection{FT-IR Spectroscopy}

FT-IR spectroscopy of control and treated cotton is presented in Figure 4. The FT-IR spectrum of control cotton showed a characteristic peak at $3408 \mathrm{~cm}^{-1}$ that was due to $-\mathrm{OH}$ stretching vibrations. This band is mainly due to polymeric O$\mathrm{H}$ or hydroxyl group associated with hydrogen bonding [30]. The absorption bands at 2910 and $2800 \mathrm{~cm}^{-1}$ were due to $\mathrm{C}-\mathrm{H}$ stretching vibrations peaks. The vibration peaks at 1460 and $1713 \mathrm{~cm}^{-1}$ were appeared due to carbonyl functional group as well as overlapping involvements of $\mathrm{C}-\mathrm{H}$ bending vibrations [31]. Boeriu et al. and Chung et al. reported that FT-IR region below 1500 is the fingerprint region and composed of additional bands that correlate mainly to carbohydrates and other bio-constituents $[32,33]$. The small peak at $883 \mathrm{~cm}^{-1}$ in the control cotton was attributed to $\beta$ glycosidic linkages between the sugar molecules in hemicelluloses and celluloses. The stretching vibration peak at $580 \mathrm{~cm}^{-1}$ was due to $-\mathrm{OH}$ out of plane bending vibrations or atmospheric $\mathrm{CO}_{2}$ (deformation vibration) contamination [34-36].

The FT-IR spectrum of treated cotton is shown in Figure 4. The vibration bands at 3430,2925 and $2852 \mathrm{~cm}^{-1}$ were mainly due to stretching vibration peaks of $-\mathrm{OH}$ and $-\mathrm{CH}$ groups in the treated sample. The FT-IR peaks at 1662 and $1431 \mathrm{~cm}^{-1}$ were attributed to the $-\mathrm{C}=\mathrm{O}$ and $-\mathrm{CH}$ bending vibrations. The peak originally present at $883 \mathrm{~cm}^{-1}$ in control sample was disappeared and merged with $-\mathrm{OH}$ bending peak in the treated cotton sample. The $-\mathrm{OH}$ out of plane bending vibration was appeared at $529 \mathrm{~cm}^{-1}$ in the treated sample. Overall, the FT-IR results showed upward shifting in hydrogen bonded $-\mathrm{OH}$ group stretching peak $3408 \rightarrow 3430 \mathrm{~cm}^{-1}$ in the treated cotton as compared to the control. It was previously suggested that the frequency $(v)$ of the vibrational peak depends on two factors i.e. force constant and reduced mass. If the mass is constant, then the frequency is directly proportional to the force constant; therefore, increase in the frequency of any bond suggested a possible enhancement in force constant of respective bond and vice versa [37]. Hence, it is assumed that biofield energy treatment might cause an increase in force constant that led to increase in the frequency of the $-\mathrm{OH}$ bond. Additionally, the carbonyl stretching peak $\left(1713-1662 \mathrm{~cm}^{-1}\right)$, $\mathrm{C}-\mathrm{H}$ bending (1460-1431 $\left.\mathrm{cm}^{-1}\right), \mathrm{OH}$ bending $\left(580-529 \mathrm{~cm}^{-1}\right)$ and $-\mathrm{OH}$ out of plane bending (580-529 $\left.\mathrm{cm}^{-1}\right)$ showed downward shift that could be due to biofield energy treatment. It is assumed here that decrease in frequency of these peaks could be due to decrease in force constant. Hence, it is assumed that biofield energy treatment had caused structural changes in the treated cotton as compared to the control.

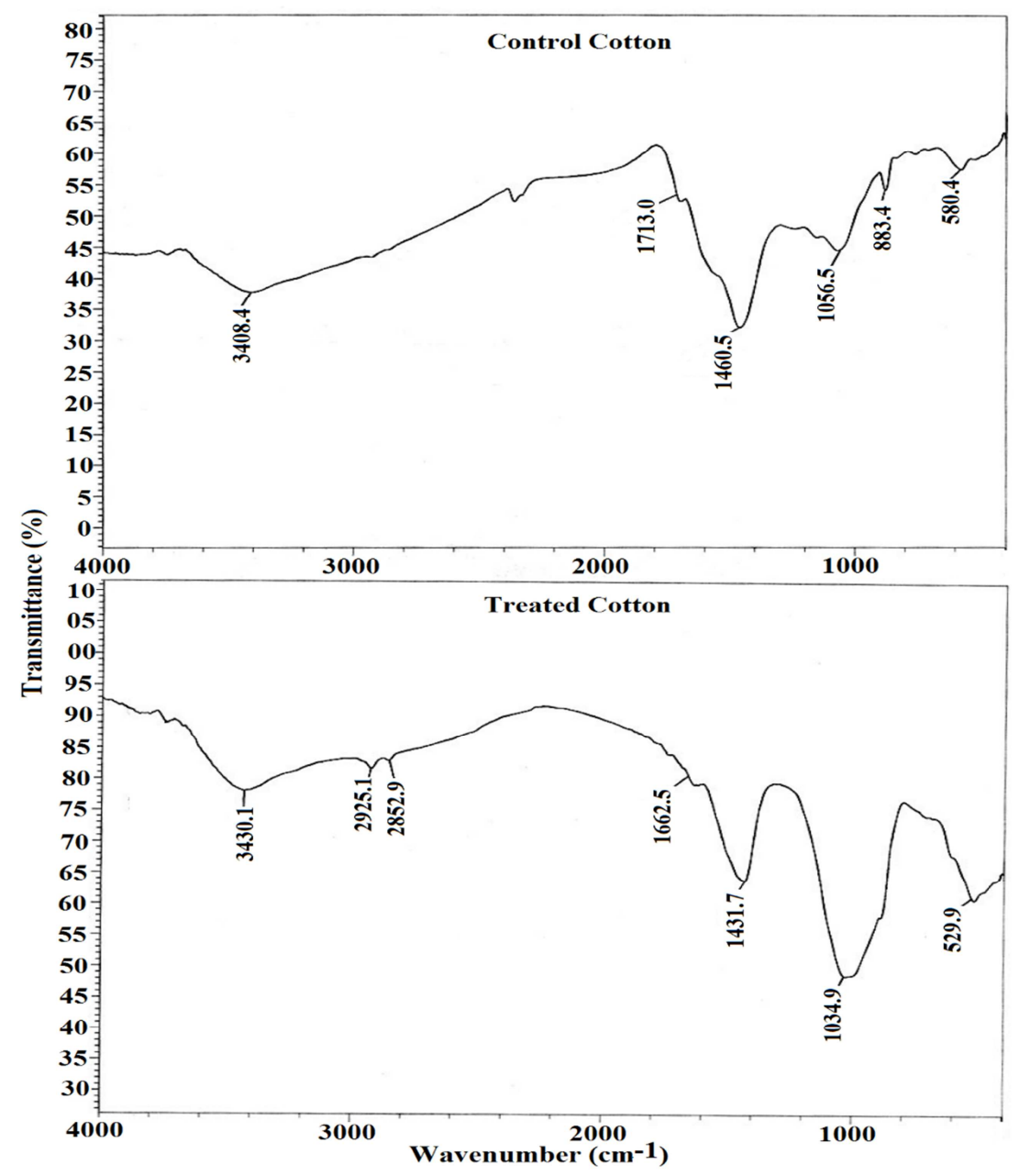

Fig. 4. FT-IR spectra of control and treated cotton. 


\subsection{CHNSO Analysis}

CHNSO analysis was conducted to determine the elemental composition of the control and treated cotton. The results are presented in the Table 1 . The percentage of nitrogen was 0.43 in the control sample and, it was increased to 0.51 in the treated cotton. The percentage of carbon was almost similar in both control (41.06) and treated cotton (40.94) samples. The hydrogen percentage was 6.06 and 5.97 in the control and treated samples, respectively. Whereas, the percentage of oxygen was 33.02 in the control sample, and it was increased slightly to 33.77 in the treated cotton. The control sample showed $2.15 \%$ of Sulphur; while no Sulphur was detected in the treated cotton. The CHNSO result suggested 19.16 and $2.27 \%$ increase in percentage nitrogen and oxygen, respectively after biofield treatment. However, the percentage carbon and hydrogen was decreased by 0.29 and $1.50 \%$ in treated cotton as compared to the control sample. It was reported that more nitrogen is required for high yield and production of cotton [38]. Hence, it is assumed that biofield treated cotton might of superior quality as compared to the control sample.

Table 1. CHNSO analysis data of control and treated cotton.

\begin{tabular}{llll}
\hline Element & Control & Treated & Percent change \\
\hline Nitrogen & 0.43 & 0.51 & 18.60 \\
Carbon & 41.06 & 40.94 & -0.29 \\
Hydrogen & 6.06 & 5.97 & -1.50 \\
Oxygen & 33.02 & 33.77 & 2.27 \\
Sulphur & 2.15 & ND & - \\
\hline
\end{tabular}

\section{Conclusions}

In summary, the DSC result showed the significant increase in an exothermic peak in treated cotton $\left(450^{\circ} \mathrm{C}\right)$ as compared to the control $\left(382^{\circ} \mathrm{C}\right)$. DTA analysis showed an increase in thermal decomposition temperature of treated cotton $\left(361^{\circ} \mathrm{C}\right)$ with respect to the control $\left(358^{\circ} \mathrm{C}\right)$. This indicated the increase in thermal stability of the biofield treated cotton. FT-IR spectroscopic analysis showed an alterations in the frequency of the treated cotton. It is presumed that biofield treatment caused changes in force constant of the treated cotton in comparison with control. Additionally, CHNSO analysis showed the considerable increase in the elemental composition of nitrogen (19.16\%) and oxygen $(2.27 \%)$ in treated cotton. Therefore, the high thermal stability of biofield energy treated cotton might improve its application for preparation of textile fabric.

\section{Abbreviations}

DSC: Differential scanning calorimetry;

TGA: Thermogravimetric analysis;

FT-IR: Fourier transform infrared spectroscopy;

PCMs: Phase change materials

\section{Acknowledgments}

The authors wish to thank all the laboratory staff of MGV Pharmacy College, Nashik for their kind assistance during handling the various instrument characterizations. The authors would also like to thank Trivedi Science, Trivedi Master Wellness and Trivedi Testimonials for their support during the work.

\section{References}

[1] True AC (1896). The cotton plant. Washington: Govt. Printing Office.

[2] Yafa S (2002) Cotton: The Biography of a Revolutionary Fiber. Penguin, USA.

[3] Bailey AE (1948) Cottonseed and cottonseed products. Wiley Interscience, New York.

[4] National Cottonseed Products Association, Inc. http:// www.cottonseed.com/publications.

[5] Yin C, Li J, Xu Q, Peng Q, Liu Y, Shen X (2007) Chemical modification of cotton cellulose in supercritical carbon dioxide: Synthesis and characterization of cellulose carbamate. Carbohydrate Polymers 67: 147-154.

[6] Kumar RS (2014) Textiles for Industrial Applications. CRC Press, Taylor \& Francis Group, Boca Raton, Florida.

[7] Shahidi S, Ghoranneviss M, Moazzenchi B, Rashidi A, Mirjalili M (2007) Investigation of antibacterial activity on cotton fabrics with cold plasma in the presence of a magnetic field. Plasma Processes and Polymers 4: S1098-S1103.

[8] Windler L, Height M and Nowack B (2013) Comparative evaluation of antimicrobials for textile applications. Environment International 53: 62-73.

[9] Mondal S (2008) Phase change materials for smart textiles-An overview. Applied Thermal Engineering 28: 1536-1550.

[10] Nelson G (2001) Microencapsulation in textile finishing. Review of Progress in Coloration and related Topics 31: 57-64.

[11] Fink HP, Weigel P, Purz HJ, Ganster J (2001) Structure formation of regenerated cellulose materials from NMMOsolutions. Progress in Polymer Science 26: 147-1524.

[12] Gorgani AS, Najafi F, Karami Z (2015) Modification of cotton fabric with a dendrimer to improve ink-jet printing process. Carbohydrate Polymers 131: 168-176.

[13] El Gendy, Eglal HK (2002) Modification of cotton fabrics via radiation graft copolymerization with acrylic acid, acrylonitrile and their mixtures. Indian Journal of Fiber and Textile Research 27: 266-273.

[14] Trivedi MK, Patil S, Tallapragada RM (2013) Effect of biofield treatment on the physical and thermal characteristics of silicon, tin and lead powders. Journal of Material Science \& Engineering 2: 125.

[15] Trivedi MK, Patil S, Tallapragada RM (2013) Effect of biofield treatment on the physical and thermal characteristics of vanadium pentoxide powders. Journal of Material Science \& Engineering S11, 001 . 
[16] Trivedi M.K, Nayak G, Patil S, Tallapragada RM, Mishra R (2015) Influence of Biofield Treatment on Physicochemical Properties of Hydroxyethyl Cellulose and Hydroxypropyl Cellulose. Molecular Pharmaceutics \& Organic Process Research 3: 126 .

[17] Barnes PM, Powell-Griner E, McFann K, Nahin RL (2004) Complementary and alternative medicine use among adults: United States, 2002. Seminars in Integrative Medicine 2: 54-71.

[18] http://www.drfranklipman.com/what-is-biofield-therapy/.

[19] Warber SL, Cornelio D, Straughn J, Kile G (2004) Biofield energy healing from the inside. The Journal of Alternative and Complementary Medicine 10: 1107-1113.

[20] Patil SA, Nayak GB, Barve SS, Tembe RP, Khan RR (2012) Impact of biofield treatment on growth and anatomical characteristics of Pogostemon cablin (Benth.). Biotechnology 11: 154-162.

[21] Trivedi MK, Patil S, Shettigar H, Bairwa K, Jana S (2015) Phenotypic and biotypic characterization of Klebsiella oxytoca: An impact of biofield treatment. Microbial and Biochemical Technology 7: 202-205.

[22] Potter C (2012) Thermal analysis of textile fibers. AATCC Review 39-45.

[23] Ibrahim SF, El-Amoudy ES, Shady KE (2011) Thermal analysis and characterization of some cellulosic fabrics dyed by a new natural dye and mordanted with different mordants. International Journal of Chemistry 3: 40-54.

[24] Clamari TA, Donaldson DJ, Thibodeaux DP (1990) Distinguishing weathered from un-weathered cotton by thermal analysis. Amer Dyest Rep 79: 42-47.

[25] Trivedi MK, Patil S, Mishra RK, Jana S (2015) Structural and physical properties of biofield treated thymol and menthol. Molecular Pharmaceutics \& Organic Process Research 3: 127.

[26] Wanna, JT, Powell JE (1993) Thermal decomposition of cotton cellulose treated with selected salts. Thermochimica Acta 226: 257-263.
[27] Yue Y (2011) A comparative study of cellulose I and II fibers and nanocrystals. (MS Thesis).

[28] Le CV, Ly NG, Postle R (1995) Heat and moisture transfer in textile assemblies. Part I steaming of wool, cotton, nylon and polyester fabric beds. Textile Research Journal 65: 203-212.

[29] Kawabata S (2000) A guide line for manufacturing ideal fabrics. International Journal of Clothing Science and Technology 11: 134-144.

[30] Coates J (2000) Interpretation of infrared spectra, a practical approach. In: Meyers, R, Ed, Encyclopedia of analytical chemistry. John Wiley \& Sons Ltd., Chichester, England.

[31] Himmelsbach DS, Akin DE, Kim J, Hardin IR (2003) Chemical structural investigation of the cotton fiber base and associated seed coat: Fourier-transform infrared mapping and histochemistry. Textile Research Journal 73: 218-288.

[32] Boeriu C, Bravo D, Gosselink RJA, van Dam JEJ (2004) Characterization of structure-dependent functional properties of lignin with infrared spectroscopy. Industrial Crops and Products 20: 205-218.

[33] Chung C, Myunghee L, Choe E (2004) Characterization of cotton fabric scouring by FT-IR ATR spectroscopy. Carbohydrate Polymers 58: 417-420.

[34] Rana AK, Basak RK, Mitra BC, Lawther M, Banerjee AN (1997) Studies of acetylation of jute using simplified procedure and its characterization. Journal of Applied Polymer Science 64: 1517-1523.

[35] Grobe A (1989) In: Brandru, J, Immergut EH, Eds, Polymer Handbook, John Wiley, New York.

[36] Günzler H, Gremlich HU (2002) IR Spectroscopy-An Introduction. Wiley-VCH, Weinheim.

[37] Pavia DL, Lampman GM, Kriz GS (2001) Introduction to spectroscopy. (3rdedn), Thomson Learning, Singapore.

[38] Livingston SD, Stichle CR (1995) Correcting Nitrogen Deficiencies in Cotton with Urea-Based Products. The Texas A\&M University System, College Station, Texas. 